\title{
The material strategy of fire-resistant tree barks
}

\author{
H. Tributsch \& S. Fiechter \\ Hahn-Meitner-Institut, Department of Solare Energetik, 14109 Berlin, \\ Germany
}

\begin{abstract}
The fire protection of organic building and thermal insulation materials is a technical challenge, for which new approaches are desirable. Exceptionally fire resistant tree barks from trees such as Sequoiadendron giganteum, Pinus canariensis and from Eucalyptus species, which evolved in fire adapted eco-systems, were studied by thermo-gravimetric techniques in combination with mass spectroscopy and complementary analysis in a temperature range up to $600^{\circ} \mathrm{C}$. It turned out that while a technical reference poymer (ABS $=$ acrylnitrilebutadien-styrole) burned by leaving only $2.6 \%$ solid, the most fire resistant tree barks only carbonized leaving up to $60 \%$ solid. It is mostly graphite and carbon, which are highly heat insulating and fire protecting as is also known from technical "foaming" graphite layers. A key chemical component that has evolved in tree barks to support fire resistance, besides other properties, is tannin, a polyphenol, which complexes macromolecules and efficiently reduces oxidants and radicals. The oxidation, in a fire, of these large planar molecules is thus suppressed to be transformed into a similarly structured graphitic component with fire retarding properties. Additional adaptations of fire resistant tree barks appear to be a fibrous micro- and nano-structure and optimised infrared optical properties. They may retard heat transfer within the bark via suppression of microscopic conduction and radiation processes.
\end{abstract}

Keywords: fire retardation, tree barks, tannins, sequoia, eucalyptus.

\section{Introduction}

Significant scientific and technological effort is presently ongoing with the aim of meeting the more and more demanding standards of fire protection when organic and plastic materials are used in our technical environments. While 
considerable experience has been gained from research, it is interesting to point out that nature during evolution was faced with a similar challenge in special environments. Trees on volcanic islands, trees that were programmed to become very old, or trees in very arid environments had to be protected against destructive damage by fire. Several parallel strategies were adopted by nature. Trees became tall to escape from the dangerous fire zone above ground. Long living seeds were stored underground or high in crowns. Seeds had to be activated by fire, which prepared a favourable environment for growth on cleared and fertilized land (Banksia). The protection of young leaves by dead organic plant remains developed (Xanthorrhoea) as well as sprouting from inside the protecting stem (Eucalyptus) and heat resistance in Savannah grasses. Important fire-protecting barriers are specially adapted tree barks, which provide the tissues outside the living cambium of the tree trunks. This cambium is a layer of cells, which are active with respect to both wood cell production towards the interior (splint wood) and to the generation of secondary bark tissues outside (bast). As described in specialized botany articles [1] and in more detail in special books on barks [2] the barks show quite complicated structures. The interior facing the splint wood is a mixture of living and dead cells, which gradually changes towards the outside by rapidly increasing the concentration of dead cells. While the bast still produced nutrients the outermost layer, the phellem, is already composed of entirely dead cells. They developed, through deposition, within the cells, of polymeric material such as suberin and cutin. In addition, minerals like calcium carbonate or silicates and especially tannins and polyphenols are typically incorporated. With increasing age, the composition of a bark can largely change, mostly due to an accumulation of discarded products from the plant metabolism. Seen from outside, a bark structure can greatly vary. In dependence of evolutionary adaptations they can have a serrated surface, which provides solar illuminated and shadowed areas side by side for a better air circulation. They can have a very smooth and bright surface in order to allow high light reflection or it may be composed of paper like sheets with included air layers for optimal thermal insulation. Generally, barks seem to have evolved so as not to heat easily in intensive sunshine [3] so that the sap water, which is transported below in the xylem is not heated to an extent that could interfere with the delicate mechanism of tensile water ascent [4].

Due to the variations found amongst barks, typical compositions are rarely given in the literature, however, it can always be assumed that cellulose is a major component because it is the structural material of the cell walls. As mentioned, suberin, which is a waxy material, is adsorbed to these cell walls. Tannins and inorganic materials like calcium oxalate or sometimes silicates are deposited in the bark cells, resins are absent in Sequoiadendron.

\section{Experimental}

\subsection{Materials and tests}

Samples of the investigated barks were collected by one of the authors (H.T.) from trees growing in their natural environments. Acrylonitrile-butadiene- 
styrene resin (ABS, Magnum 9010 ABS natural, Dow chemicals, USA) was used as a reference polymer in this study as received (high-impact polystyrene (HIPS, $M_{w}=240000, M_{n}=65000$, butadiene rubber content $10 \%$, graft ratio $120 \%$, Cheil Industries, South Korea, behaved similarly, but is not discussed here). Tannin, extracted from the Quebracho tree, was purchased from Aldrich, tannin from Pinus canariensis and Sequoiadendron was extracted with an acetone/water mixture at $50^{\circ} \mathrm{C}$ using ultrasound.

ABS was mixed with tannin in a bowl mixer (60 r.p.m., 5 min) at $200^{\circ} \mathrm{C}$. Bar specimens for the combustion tests were cut from slabs prepared by pressing at $200^{\circ} \mathrm{C}$. The pure ABS used as a standard was treated in the same way.

Combustion performance of the formulations was studied either by the oxygen index test (limiting oxygen index, LOI) following the ASTM D 2863 standard (the test determines the oxygen concentration at which sustained combustion occurs using a vertically mounted specimen ignited at the upper end) or by the UL94 standard on 1/16 inch specimens in the vertical configuration (the test rates materials on the basis of their ability to resist combustion on repeated application of a flame at the lower end of the vertically positioned test specimen).

\subsection{Instruments used for measurements}

Thermogravimetric measurements were carried out in a Netzsch Simultaneous ThermalA STA 409C connected with a quadrupole mass spectrometer via a skimmer coupling system. Thermogravimetric changes could be detected simultaneously with the amount of gas species evolved from the sample. The measurements were performed in an $\mathrm{Al}_{2} \mathrm{O}_{3}$ sample crucible under a continuous flow of $\operatorname{argon}\left(100 \mathrm{~cm}^{3}\right.$ per min) with a heating rate of $10^{\circ} \mathrm{C}$ per min.

For the measurement of IR spectra in the spectral region 2-25 $\mu \mathrm{m}$ a photometric infrared ellipsometer was used, which was coupled with a Fouriertransform spectrometer (Bruker IFS55).

\section{Fire resistance in natural environments}

In natural environments, fires typically are not stationary processes attaining high temperatures, but are relatively rapidly passing events, which near the ground only attain temperatures of $50-150{ }^{\circ} \mathrm{C}$ and, depending on the vegetation, maybe $500-600^{\circ} \mathrm{C}$ in $5 \mathrm{~m}$ elevation. Our attention concentrated on barks of trees, which reportedly have demonstrated a high survival resistance with respect to frequent fire (fig. 1). The trees selected include: 1. Pinus canariensis: The Canarian pine (fig. 1a) has evolved on the volcanic Canarian Islands and has continuously been exposed to fire generated by volcanic eruptions. Its fire resistance and ability to sprout again after fires is documented [5]. 2 . Sequoiadendron giganteum: The giant sequoia (fig. 1b) lives in selected mountain areas in California. It reaches an age of 2-3000 years and is protected by bark up to $30 \mathrm{~cm}$ thick. This bark is resin free and very resistant against biological decay. After 300 years the bark can still be present while the wood 
below has degraded. While fire can damage the sequoia trees (compare fig 1b), they are known to resist and even to take advantage of frequent fires in their ecological environment [6]. 3. Eucalyptus species: The dry inland of Australia is frequently hit by lightening, which may cause extended fires. Eucalyptus trees are adapted to fire and may even to some extent promote fire such as "stringybarks" with their bark hanging in long, fibrous stringers [7]. Some eucalyptus also shed their bark as they burn in order to get rid of the heat source. During the 50000-year-old colonization of Australia, its aboriginal people have been using fire regularly to optimise the land with respect to increased animal and plant crop harvests. It is known that eucalyptus forests, while burning vigorously can sprout again rapidly, which indicates that the barks are effectively protecting living cells underneath [8].
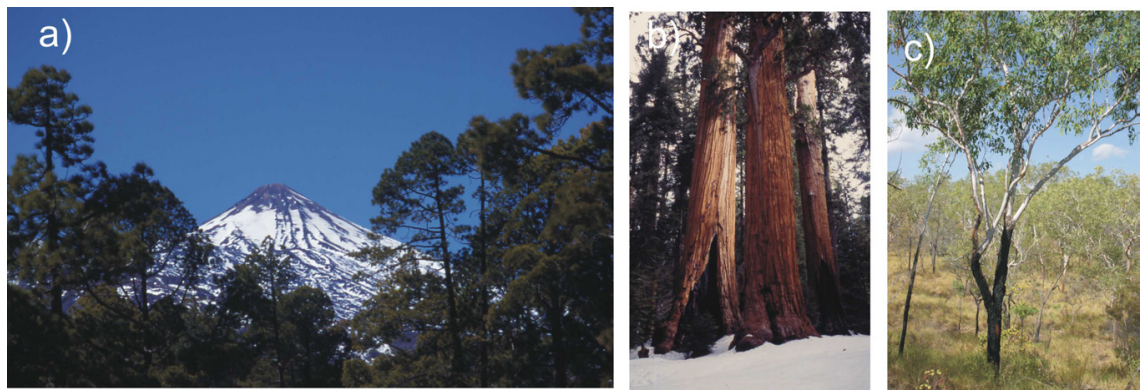

Figure 1: Pinus canariensis (a), Sequoiadendron giganteum (b), and a Eucalyptus species (c) from Australian's Northern Territory (Edith Falls).

From Eucalyptus bush fires it is known that trees with undamaged bark can safeguard a tree for renewed sprouting. When, however, the tree bark is damaged the wood will start to burn from inside out, which may lead to severe damage and to the destruction of the entire tree.

\section{Results}

When a larger compact piece of Sequoia bark is taken and exposed to fire the surface carbonises rapidly. The oxidation, however, does not continue to proceed if the fire is removed. Only after very long and intensive heating in a fire the bark starts to glimmer and continues to glow after the external flames seize to heat the bark. Only very rarely flames are seen during such a gradual oxidation process. If, on the other hand, very small samples of the Sequoia bark are taken, the flames preferably oxidize the very fine structured material and leave more coarse structured fibres behind. During such a process, the fine structured scale may form a layer of ash. The layer becomes thicker until the entire sample is oxidised. A different combustion behaviour is observed when the bark sample is exposed to a very high temperature with limited access to oxygen. In this case the sample is only carbonised but will not continue to glow and oxidise. Under 
the lack of oxygen the carbonised layer apparently shields the underlying bark from oxidation.

In order to understand the combustion process in a more quantitative way, well-defined samples of bark were studied in a thermal gravimetric set-up, which was combined with mass spectroscopy and the temperature gradually and linearly raised $\left(10^{\circ} \mathrm{C}\right.$ per $\left.\mathrm{min}\right)$ up to $600^{\circ} \mathrm{C}$. The experiments were performed in an argon stream in order to understand how the material behaves under high temperature in the presence of lack of oxygen access. For comparison a corresponding sample of the plastic compound ABS (Acrylnitryl Butadien Styrol) was tested. At $500-600^{\circ} \mathrm{C}$ only $2.6 \%$ of the solid material remained in this case (fig. 2). High-impact polystyrene (HIPS) behaved in a similar way.

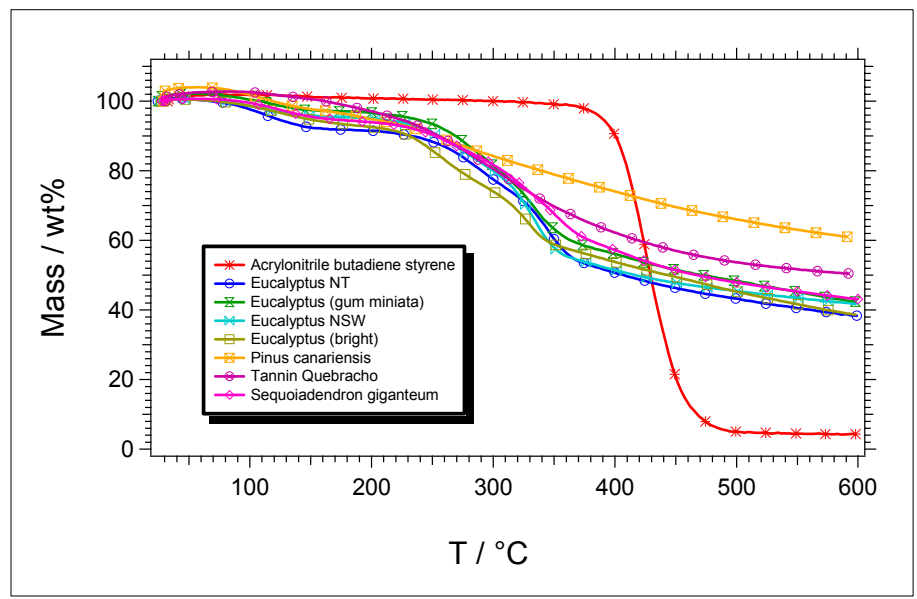

Figure 2: Comparison of thermogravimetric mass loss for ABS, different barks and tannin (Eucalyptus NT corresponds to fig 1c).

In fig. 2 it is seen that tree barks, which are known to be fire resistant at $600^{\circ} \mathrm{C}$ still leave a significant quantity of carbonised solid material when reaching $600^{\circ} \mathrm{C}$. In the case of Sequoiadendron giganteum it amounts to $43 \%$, in the case of Pinus canariensis $61 \%$, and in the case of a typical Eucalyptus tree bark (taken from different regions in Australia) a solid mass fraction of $40 \%$ is still left. In contrast, ABS, our reference plastic material, (and also HIPS) only left a few per cent solid under identical conditions. Because tannin was suspected to be involved in the formation of the solid product, experiments were also performed with tannin (extracted from the bark of the Quebracho tree) Fig. 2 shows that the solid mass retained in this case reaches $49.5 \%$. Tannin extracted from Sequoiadendron giganteum showed a similar behaviour. The mass spectroscopically measured gases escaping from Sequiadendron giganteum during thermogravimetric heating are shown in fig. 3 . While up to $100^{\circ} \mathrm{C}$ mostly water vapour leaves the sample, oxidized compounds such as $\mathrm{CO}$ and $\mathrm{CO}_{2}$ follow at $200-300^{\circ} \mathrm{C}$. Organic compounds (mass 107/108) are additionally detected starting below $200^{\circ} \mathrm{C}$. 


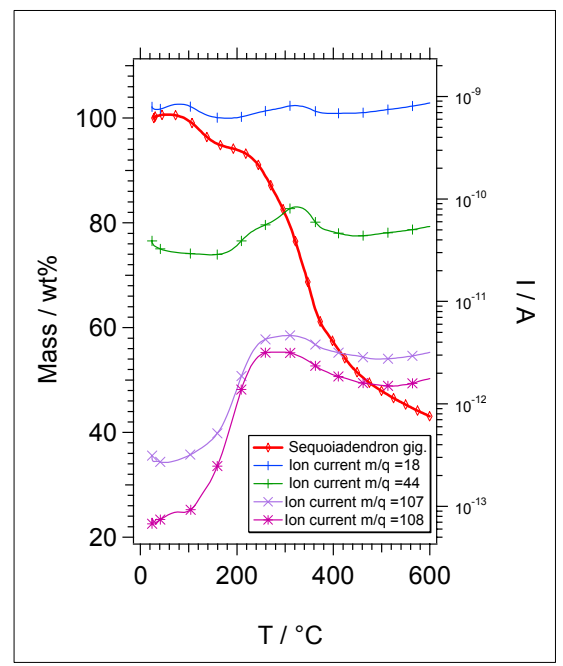

Figure 3: Temperature dependent mass spectroscopically determined gases escaping from Sequiadendron giganteum bark.

Even though mixing in a bowl mixer will only generate limited molecular contact between solids, in a mixture of ABS with tannin (fig. 4, left and right) the characteristic steep drop during ABS volatilization between 400 and $450^{\circ} \mathrm{C}$ occurs earlier, indicating that tannin (polyphenol) provokes a modification of the polymer behaviour. In addition, a somewhat higher proportion of unburned solid is observed ( $27 \%$ for $50 \%$ tannin plus $50 \%$ ABS versus $48 \%$ with tannin alone). When tannin is replaced by Pinus canariensis bark, a similar earlier downshift is observed near $400^{\circ} \mathrm{C}$ and a higher fraction of solid remains (35\% for a $50: 50 \%$ mixture with ABS versus $61 \%$ for pure bark (fig. 4, right)). The fire retarding activity of tannin was also studied by means of limiting oxygen index LOI and UL94 flammability tests. The addition of tannin increases the LOI index. The formation of insulating char on the surface of the burning polymers was observed in the experiments. This may be the reason why tannin helps to achieve non-dripping behaviour in the UL94 test, probably by interacting with and adhering to the surface of the polymers.

In order to elucidate the chemistry of fire retardation, charred tree barks were investigated using XRD techniques. Fig. 5 shows the XRD spectrum obtained for Pinus canariensis bark after heating in argon up to $600^{\circ} \mathrm{C}$. The charred tree bark exhibits sharp lines at $2 \theta=26.5^{\circ}$ and $43.5^{\circ}$. They are clearly attributable to larger graphite particles $(\geq 100 \mathrm{~nm})$. The broad peak around $2 \theta \approx 22^{\circ}$ originates from small graphite particles or graphene layers with extended distances between lattice plains, apparently caused by inserted molecules. There is an intriguing additional sharp line near $2 \theta=30^{\circ}$, which, interestingly, the computer fitting program attributes to a rare metastable $\mathrm{C} 8$ carbon configuration. It has been identified by Natushenko et al [9] during carbon plasma deposition and attributed to a "super-cuban" structure. However, an alternative $\gamma-\mathrm{Si}$ structure has equally been proposed for this XRD line [10]. 


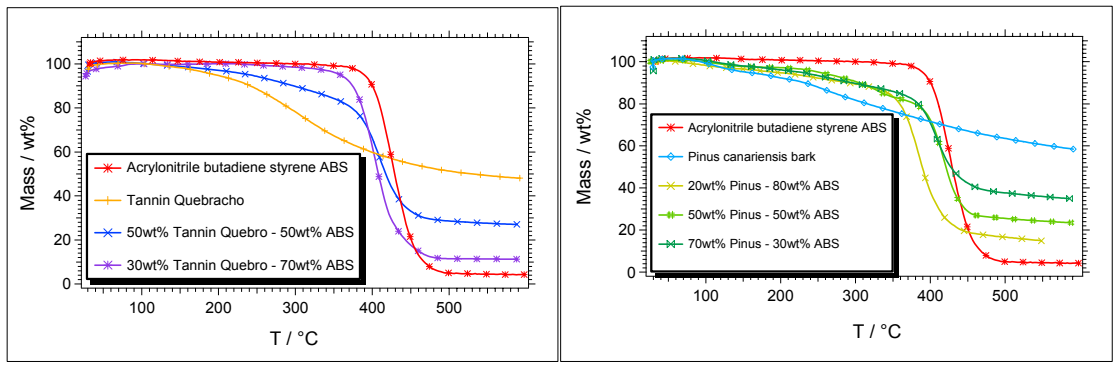

Figure 4: Thermogravimetric measurements of mixtures of tannin from Quebracho (left) and Pinus canariensis bark (right) with ABS.

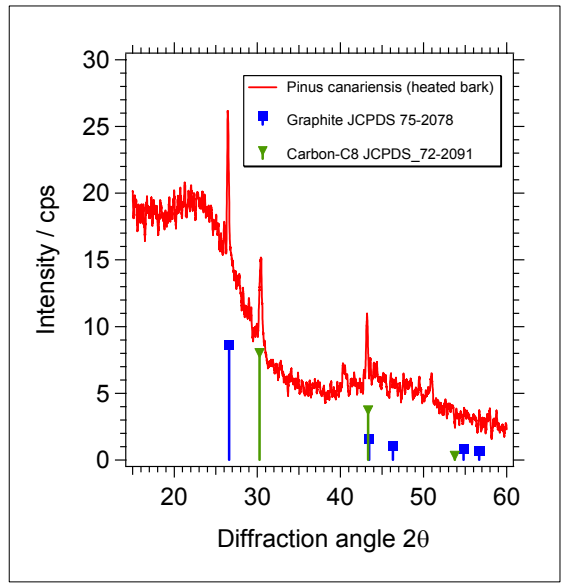

Figure 5: $\quad$ XRD - spectrum of charred Pinus canariensis. No XRD pattern was found in the fresh bark.

A remarkable structural property of the fire resistant tree bark of Sequiadendron giganteum is its fibrous architecture with thin scales of semi-transparent thin membranes attached to it. The propagating heat of fire would have to penetrate many air filled spaces with bordering membranes with high tannin content. Air has a low heat transfer coefficient and, when confined to micro-volumes in a spongy material, effectively limits heat transfer through convection. In order to assess its ability to deal with heat radiation, the infrared absorption properties of tannins were studied (fig. 6). A significant absorption band is found between 6 and $10 \mu \mathrm{m}$, where most heat radiation is expected to occur from a heat source of 50 to $150^{\circ} \mathrm{C}$. It is known that the maximum thermal emission of IR radiation will be found in a material with maximum IR absorption in this spectral range. The tannin containing bark will thus absorb infrared radiation, protecting living plant cells below. But when heated, it will strongly reemit radiation, thereby keeping its temperature low. Since this occurs in many steps, a retardation of the fire front in adapted barks is expected on the basis of 




Figure 6: Absorption of tannin from Pinus canariensis and Quebracho in the infrared, which facilitates efficient thermal emission.


Figure 7: Scheme explaining the fire resistance strategy of tree barks via polyphenols (tannins) through carbonisation (left) and (thermo)reduction of radicals (right).

optimized microscopic structure. Comparative heating experiments with IR thermography confirmed that Sequoiadendron giganteum tree bark is a much better thermal insulator than birch tree bark or a comparative slab of ABS.

\section{Discussion}

Tree barks of fire resistant trees during a fire aim at maximizing the fraction of unburned, charred remains (fig. 7). These are, in the case of Pinus canariensis mostly graphite, inserted and distorted graphite-graphene aggregates and a rare carbon C8 species. Graphite-carbon layers are known to be very poor heat conductors and, "foaming graphite" layers have already found technical application $[11,12]$. A remarkable fact is that nature is using a structurally very similar planar compound, tannin or polyphenol, to generate graphite during 
charring. These polyphenols have additional properties which make them interesting for a fight against fire and volatile radicals generated by fire: They have been reported to reach molecular weights of up to 20.000 and are known to form complexes with proteins and alkaloids, which they precipitate (this property is used in tanning).

But they also form complexes with polysaccharides, which are contained in tree barks in the form of cellulose. In addition, tannins are known to act as antioxidants and to neutralize radicals via their electron donation ability [13-15]. During a fire polyphenols may chemically reduce and inactivate radicals formed, which otherwise would disrupt and ignite materials. Recently it was discovered that polyphenols (tannins) can also donate electrons from their excited state, in which they generate correspondingly higher reducing power [16] (fig. 7). Thermally generated radiation, propagating through a tannin containing bark may therefore produce a wave of increased reducing power, which could retard and slow down the fire front. The results presented here also show tannin as a charring agent for styrenic polymers. It increases their fire retarding properties by decreasing the polymer's volatilization causing char formation and by formation of a protective layer against the heat of the flame and against diffusion to the flame of combustible volatile compounds. Since there is a significant variation in quantity and quality of tannins in tree barks [17] more studies are required to find out what additional chemical factors are active in fire retarding tree barks. Thermo-chemical model experiments with tannins may be helpful in broadening our knowledge on fire retardation. All together this study into natural adaptation against fire has shown that a bio-analogue, a bionic research strategy may be promising.

\section{Acknowledgements}

The cooperation of Dr. A.J. Balabanovich and of Mr. J. Went who participated in part of the experiments is gratefully acknowledged. The IR-measurement of tannins was provided by Dr. W. Henrion. Tannin extraction was performed by Dr. J. Rojas-Chapana.

\section{References}

[1] Holdheide W. Anatomie mitteleuropäischer Gehölzrinden. In: H. Freund: Handbuch der Mikroskopie und Technik. Umschau Verlag, Frankfurt/M.: 193-367

[2] Vaucher F., (1992) Baumrinden (Tree barks), Ferdinand Enke Verlag, Stuttgart

[3] Henrion W., Tributsch H., Solar Energy Materials, Solar Cells, to be published

[4] Tributsch H., Nadezdhina N., Cermak J., J. Phys. Chem. B 109 (2005) 17693

[5] Lüpnitz D., Mitteilungen der Deutschen Dendrologischen Gesellschaft ISSN: 0070-3958, Germany, 1999, (no.84) p. 23-38 
[6] Harvey, H. T; Shellhammer, H. S.; Stecker, R. E. 1980. Giant sequoia ecology: Fire and reproduction. Scientific Monograph Series No 12. Washington, DC: U.S. Department of the Interior, National Park Service. $182 \mathrm{p}$.

[7] Pyne, S. J. 1991. Burning Bush - A Fire History of Australia._New York: Henry Holt and Company.

[8] Whelan, Robert J. 1995. The Ecology of Fire. New York: Cambridge University Press.

[9] Natyushenko, N.N., Strelnitsky, V.E., Gusev, V.A., Kristallographiya 26 (1981) 484

[10] Johnston, R.., Hoffmann R., J. Am. Chem. Soc.111 (1989) 810

[11] Chang W., Scriven R, Blair-Ross R; (1975), Flame-Retardant Organic Coatings" in Lewis M. ed. Flame-Retardant Polymeric Materials. Vol.1 Plenum Press

[12] Archodoulaki, V-M, (1993) Dissertation, Mining-University Leoben (Austria)

[13] Haslam, E. Plant Polyphenols, Vegetable Tannins Revisited, Cambridge University Press 1989

[14] Hagermann, A.E., Carlson, D.M., in Recent research Developments in Agricultural and Food Chemistry 2 (1998) 689

[15] Hemmingway, R.W., Lacks, P.E (eds), Plant Polyphenols: Synthesis, Properties, Significance; Plenum Press, N.Y. 1992;

[16] Podzuweit R, Tributsch, H. in preparation

[17] Hernes, P.J., Hedges, J.I., Geochim. et Cosmochim. Acta 68 (2004) 1293 